\title{
Molecular traceability of beef from synthetic Mexican bovine breeds
}

R. Rodríguez-Ramírez ${ }^{1}$, A. Arana ${ }^{2}$, L. Alfonso ${ }^{2}$, A.F. González-Córdova ${ }^{1}$, G. Torrescano $^{3}$, I. Guerrero Legarreta ${ }^{4}$ and B. Vallejo-Cordoba ${ }^{1}$

${ }^{1}$ Laboratorio de Calidad, Autenticidad y Trazabilidad de los Alimentos, Centro de Investigación en Alimentación y Desarrollo A.C.,

Hermosillo Sonora, México

${ }^{2}$ Departamento de Producción Agraria, Universidad Pública de Navarra, Campus de Arrosadía, Pamplona, España

${ }^{3}$ Laboratorio de Ciencia de la Carne, Coordinación de Tecnología de Alimentos de Origen Animal, Centro de Investigación en Alimentación y Desarrollo A.C., Hermosillo Sonora, México

${ }^{4}$ Departamento de Biotecnología, Universidad Autónoma Metropolitana, Unidad Iztapalapa, Vicentina, México

Corresponding author: B. Vallejo-Cordoba

E-mail: vallejo@ciad.mx

Genet. Mol. Res. 10 (4): 2358-2365 (2011)

Received December 2, 2010

Accepted June 1, 2011

Published October 6, 2011

DOI http://dx.doi.org/10.4238/2011.October.6.1

ABSTRACT. Traceability ensures a link between carcass, quarters or cuts of beef and the individual animal or the group of animals from which they are derived. Meat traceability is an essential tool for successful identification and recall of contaminated products from the market during a food crisis. Meat traceability is also extremely important for protection and value enhancement of good-quality brands. Molecular meat traceability would allow verification of conventional methods used for beef tracing in synthetic Mexican bovine breeds. We evaluated a set of 11 microsatellites for their ability to identify animals belonging to these synthetic breeds, Brangus and Charolais/ 
Brahman (78 animals). Seven microsatellite markers allowed sample discrimination with a match probability, defined as the probability of finding two individuals sharing by chance the same genotypic profile, of $10^{-8}$. The practical application of the marker set was evaluated by testing eight samples from carcasses and pieces of meat at the slaughterhouse and at the point of sale. The DNA profiles of the two samples obtained at these two different points in the productioncommercialization chain always proved that they came from the same animal.

Key words: Meat traceability; Microsatellite markers; Synthetic breeds

\section{INTRODUCTION}

Food safety and food quality have become a priority for consumers and meat producers. To guarantee both quality and safety, it must be possible to follow the path of a specified piece of meat back to any point in the supply chain (Vázquez et al., 2004). The meat industry has responded globally to a series of crises such as bovine spongiform encephalopathy, labeling scandals and outbreaks of enterohemorrhagic Escherichia coli infections. As a consequence, considerable effort has been expended to develop meat traceability schemes that document the origin and movement of animals and their parts along all or part of the food supply chain. Such schemes are now required by regulations in the European Union and Japan (Vetharaniam et al., 2009). Likewise, in Latin American countries such as Uruguay, Brazil, Argentina, Chile, and Mexico, where the beef export market is important, animal identification was introduced as a first step in the implementation of a meat traceability system (Rodríguez-Ramírez et al., 2011). Internationally, the USA is lagging behind many countries in developing traceability systems for food in general and especially for livestock (Smith et al., 2005).

Traceability is critical for the successful identification and recall of contaminated products from the market during a food crisis and as a support for quality assurance. Additionally, traceability is also extremely important for the protection and value enhancement of brands, especially in niche markets (Vetharaniam et al., 2009). For example, a label such as Ternera de Navarra (Beef of Navarra), a protected geographical indication (PGI) in the North of Spain, is certified by using DNA markers (Arana et al., 2002). The concept of traceability throughout the food supply chain is recognized within the European Union with the regulation (EC) No. 178/2002, in which traceability is defined as the ability to trace and follow food, feed and ingredients through all stages of production, processing and distribution (Orru et al., 2006). These regulations seek to guarantee a traceability system that ensures a link between the carcass, quarters or pieces of beef and the individual animal or the group of animals from which they are derived. Therefore, traceability is achieved by making use of identification labels attached to live animals and meat products throughout the productioncommercialization chain (Vázquez et al., 2004).

As a consequence, traceability requires systems for animal identification and registration and for labeling animal products. Such information is normally obtained by ear tagging the animals, by labeling food and feed placed on the market and by producing docu- 
ments that allow the identification of all parts in the operation. However, with these methods fraud cannot be completely prevented (Orru et al., 2006). On the contrary, DNA-based traceability systems or molecular traceability offer an unequivocal verification tool (Arana et al., 2002). Meat traceability studies differing in the number of microsatellites used, optimization of PCR conditions aiming at carrying out multiplex reactions and cattle breeds were recently reviewed (Rodríguez-Ramírez et al., 2011). While in one study, eight microsatellites were used for the certification of Ternera de Navarra (Beef of Navarra) from the Pirenaica breed (Arana et al., 2002), other studies evaluated a larger number of microsatellites in several Italian cattle breeds (Orru et al., 2006; Dalvit et al., 2008a,b). In one study, 21 microsatellites were tested for breed identification in four native Italian cattle breeds (Dalvit et al., 2008a); the marker sets with the highest gene diversity were shown to perform best. As a result, the same group evaluated 12 microsatellites in six Italian cattle breeds aiming at reducing the costs of the analysis but considering genetic differentiation among them and found that a set of 8 microsatellites showed reliable results (Dalvit et al., 2008b). In all these studies pure cattle breeds were evaluated. However, in Mexico beef is derived from synthetic bovine breeds, such as Brangus, Brahman (Méndez et al., 2009) and Charolais. Synthetic breeds were developed by crossing zebu and taurine cattle and were claimed to be both highly resistant to heat like Indian cattle and highly productive like European cattle (Bicalho et al., 2006). Thus, the objective of this study was to select a subset of microsatellite markers from a panel of 11 for the establishment of meat molecular traceability for beef from Mexican synthetic bovine breeds. Additionally, the practical application of the traceability system was tested with samples collected from the retail market.

\section{MATERIAL AND METHODS}

\section{Population studied}

Seventy-eight animals of synthetic cattle breeds from two different slaughterhouses were included in the study. Additionally, four meat samples were collected from the local market where this beef is commercialized. Blood and muscle tissue samples were frozen at $-20^{\circ} \mathrm{C}$ until DNA extraction was carried out.

\section{DNA analysis}

Muscle tissue $(100 \mathrm{mg})$ was homogenized in $680 \mu \mathrm{L}$ lysis buffer $(50 \mathrm{mM}$ Tris- $\mathrm{HCl}$, $100 \mathrm{mM} \mathrm{NaCl}, 100 \mathrm{mM}$ EDTA, $1 \%$ SDS). Then, $20 \mu \mathrm{L}$ proteinase $\mathrm{K}$ was added and the homogeneate was incubated at $62^{\circ} \mathrm{C}$ for $90 \mathrm{~min}$. DNA purification was carried out by the chroroform-isoamylic alcohol standard protocol. DNA from blood samples $(100 \mu \mathrm{L})$ was extracted using a commercial kit (Wizard Genomic, Promega, Wisconsin, USA). DNA from each individual was independently typed for 11 microsatellites (Table 1). From the microsatellites evaluated, nine were those recommended by the International marker set of ISAG. The primer sequence of the microsatellites can be found on the webpage www.isag.org.uk/journal/ comparisonguide. PCRs were carried out by using a commercial kit of fluorescent primers following manufacturer instructions (Stock Marks, Applied Biosystems, Foster City, CA, USA). PCRs were carried out using a thermocycler (9700 Applied Biosystems, San Diego, CA, USA) 
with the following conditions: an initial denaturation step of $15 \mathrm{~min}$ at $95^{\circ} \mathrm{C}$ and 31 cycles as follows: $45 \mathrm{~s}$ at $94^{\circ} \mathrm{C}, 45 \mathrm{~s}$ at $61^{\circ} \mathrm{C}$ with a $30 \mathrm{~s}$ ramp, $60 \mathrm{~s}$ at $72^{\circ} \mathrm{C}$ with a $30 \mathrm{~s} \mathrm{ramp}, 1$ cycle of 60 min at $72^{\circ} \mathrm{C}$, and 1 cycle of $2 \mathrm{~h}$ at $25^{\circ} \mathrm{C}$. PCR products were analyzed using an ABI PRISM 310 Genetic Analyzer (Applied Biosystems, San Diego, CA, USA). Sequencing profiles were analyzed by using Genescan and Genotyper softwares (Applied Biosystems).

\begin{tabular}{lcc} 
Table 1. Microsatellites evaluated in Mexican synthetic bovine breed. \\
\hline Marker & Chromosome & Fragment size (bp) \\
\hline TGLA227 & 18 & $74-104$ \\
BM2113 & 2 & $125-143$ \\
TGLA53 & 16 & $144-190$ \\
ETH10 & 4 & $210-226$ \\
SPS115 & 15 & $240-262$ \\
TGLA126 & 20 & $109-127$ \\
TGLA122 & 21 & $130-164$ \\
INRA23 & 3 & $197-223$ \\
ETH3 & 19 & $117-129$ \\
ETH225 & 9 & $140-156$ \\
BM1824 & 1 & $178-190$ \\
\hline
\end{tabular}

\section{Statistical analysis}

Genetic variability of markers was analyzed in an effort to validate the selected microsatellites. Average heterozygocity $(\mathrm{H})$ and average polymorphism information content (PIC) were calculated with the Molkin 3.0 software (Gutiérrez et al., 2005). Values of match probability (MP), defined as the probability of finding two individuals sharing by chance the same genotypic profile, were calculated according to Weir (1996) and Arana et al. (2002). Match probability values were calculated using different marker sets, starting with the most polymorphic marker and adding sequentially the next most polymorphic.

\section{RESULTS AND DISCUSSION}

Allele frequencies, $\mathrm{H}$ and PIC for the markers analyzed in the Mexican synthetic bovine breed are shown in Table 2 . All microsatellites evaluated were polymorphic and contained between five and 19 alleles. PIC and $\mathrm{H}$ data showed that the least polymorphic marker was BM1824, with values of 65.2 and 70.1, respectively. On the other hand, the most polymorphic marker was BM2113, with values of 84.2 and 85.8 for PIC and H, respectively. Other authors also reported very low values for the marker BM1824 (PIC = 55.9) in cattle from the pure Italian breed Chianina (Orru et al., 2006). On the other hand, BM1824 was not the least polymorphic when it was evaluated in beef from the Pirenaica breed (Arana et al., 2002) and Asturiana de los Valles and Asturiana de la Montaña breeds (Vázquez et al., 2004).

MP with a different number of markers for the population under study is shown in Figure 1. The MP value for the most polymorphic marker (BM2113) was 3.66. On the other hand, the MP value for the 11 markers was $1.149 \times 10^{-11}$. These results were similar to those reported by other authors for Spanish (Vázquez et al., 2004) and Italian breeds (Orru et al., 2006; Dalvit et al., 2008a,b). As expected, MP diminishes with an increasing number of markers, down to 
R. Rodríguez-Ramírez et al.

2362

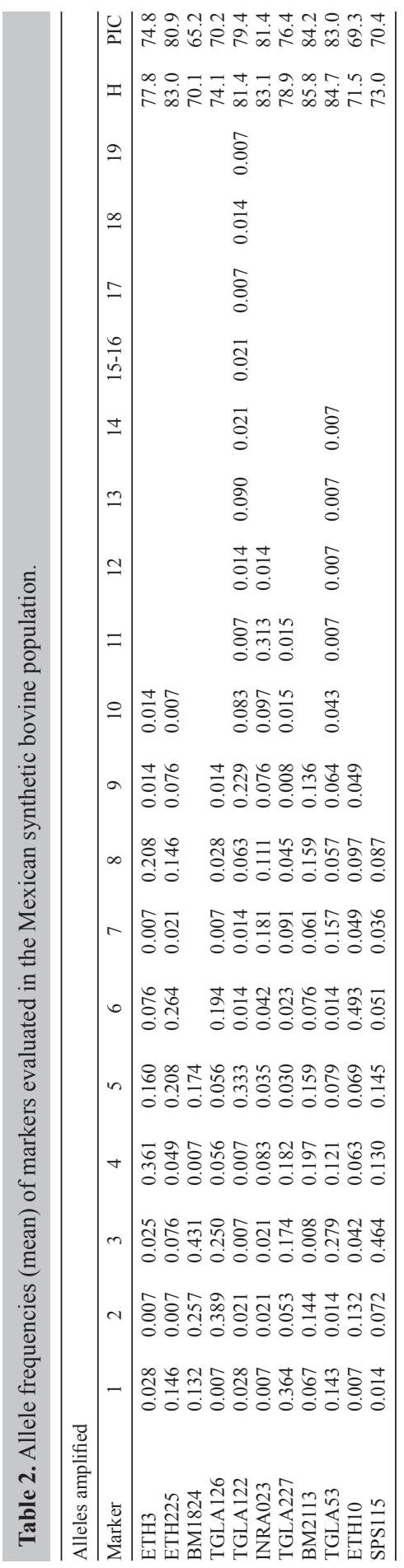

Genetics and Molecular Research 10 (4): 2358-2365 (2011) 
a probability of $10^{-11}$. Results showed that the probability of two different animals sharing the same allelic profile (MP) was $9.96 \times 10^{-8}$ with a set of seven markers. Similarly, other studies showed an MP of $10^{-8}$ when eight markers were used (Arana et al., 2002; Dalvit et al., 2008b). However, others have reported the use of six markers with an MP of $10^{-4}$ in an effort to reduce testing costs (Vázquez et al., 2004). In this study, a set consisting of seven markers was found to be suitable for meat traceability studies. To test the reliability of the marker set for meat traceability, the task consisted in determining whether or not two samples obtained at different points along the production-commercialization chain are from the same animal. To resolve this question, allelic profiles obtained from samples collected from the point of sale and the slaughterhouse were compared. A typical allelic profile showing that a sample collected in the slaughterhouse (Figure 2A) and the point of sale (Figure 2B) coincided in all alleles is presented in Figure 2. All meat samples collected from the market were correctly identified. Thus, it was concluded that the meat samples collected from the point of sale corresponded to the animal tested at the slaughterhouse. The error rate of the test using seven microsatellites was $<0.01 \%$. It has been recommended that by testing sufficient microsatellites, the probability of making an error should be no greater than $0.01 \%$ (Cunningham and Meghen, 2001).

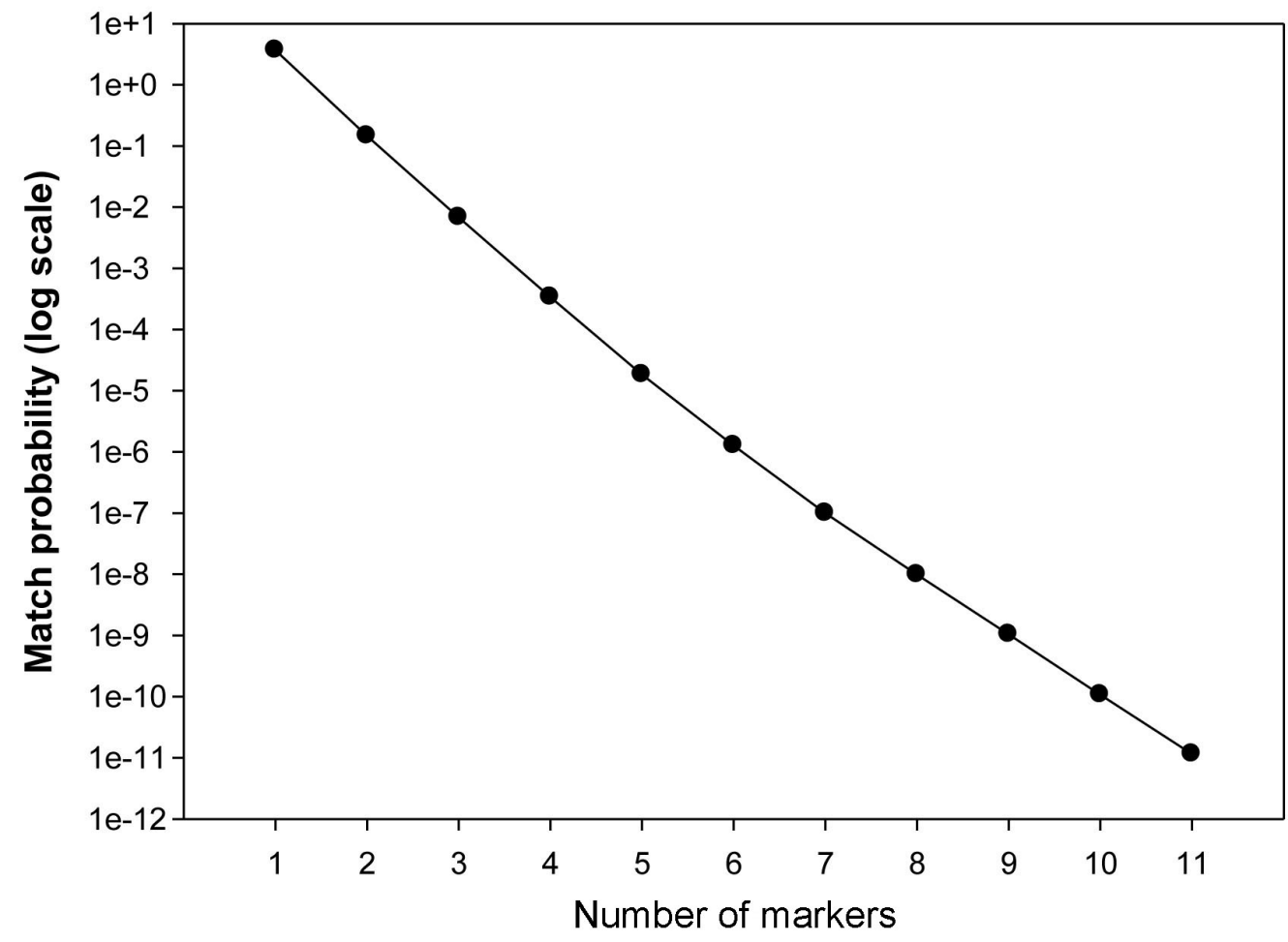

Figure 1. Probability of two samples matching by chance as a function of the number of microsatellite markers evaluated. 


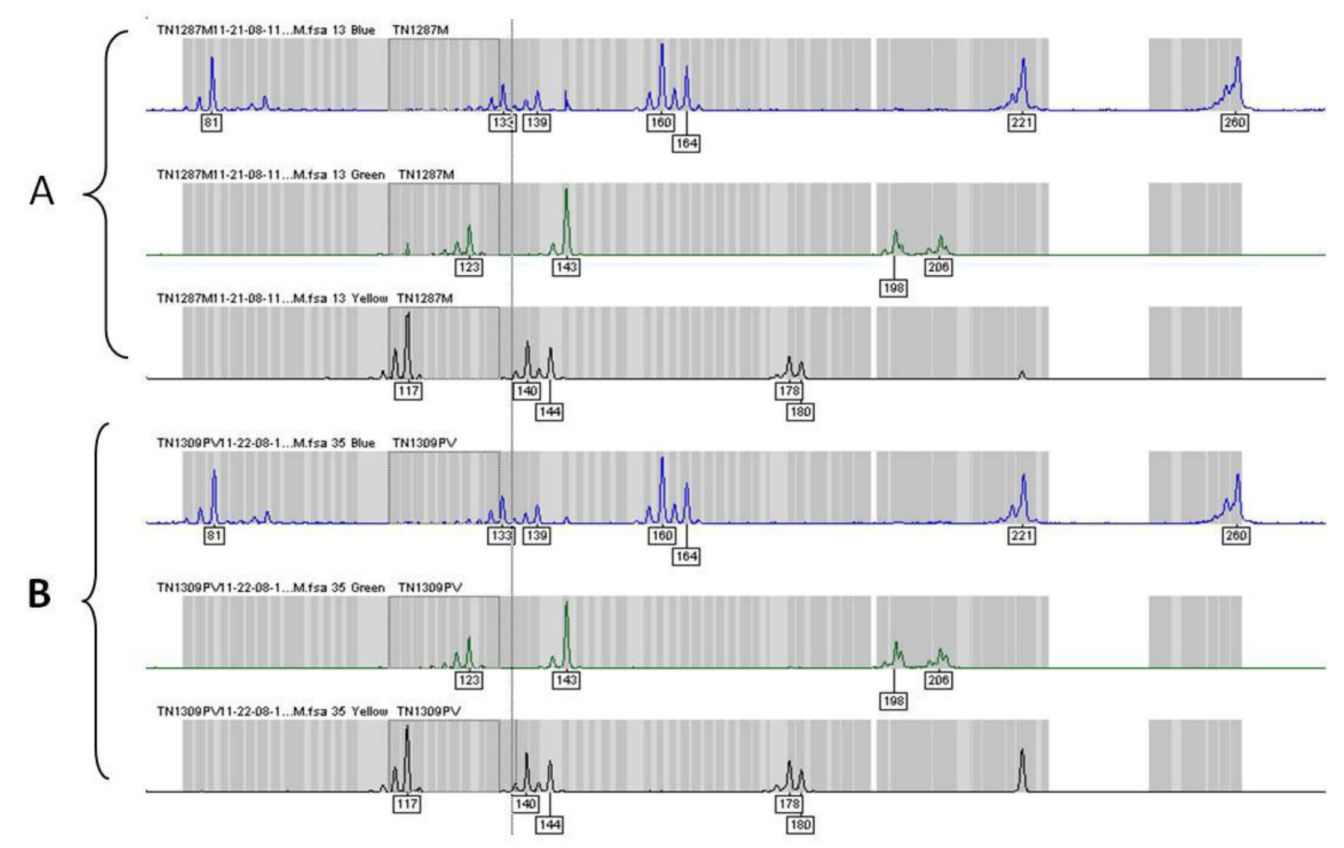

Figure 2. Allelic profiles of microsatellite markers obtained from samples collected from the productioncommercialization chain. A. A sample collected from the slaughterhouse. B. A sample collected from the point of sale.

\section{CONCLUSIONS}

The verification of meat traceability in synthetic bovine Mexican breeds may be reliably carried out with a subset of seven microsatellite markers from the eleven markers evaluated. Additionally, the usefulness of molecular traceability was shown by comparing samples collected from different locations of the production-commercialization chain.

\section{ACKNOWLEDGMENTS}

Research supported by grant \#122204 "Apoyos Complementarios para la Actualización de Equipo Científico 2009" from Consejo Nacional de Ciencia y Tecnología (CONACyT). The technical assistance of Lilia María Beltrán-Barrientos and María de Jesús Torres-Llanez is gratefully recognized.

\section{REFERENCES}

Arana A, Soret B, Lasa I and Alfonso L (2002). Meat traceability using DNA markers: application to the beef industry. Meat Sci. 61: 367-373.

Bicalho HM, Pimenta CG, Mendes IK, Pena HB, et al. (2006). Determination of ancestral proportions in synthetic bovine breeds using commonly employed microsatellite markers. Genet. Mol. Res. 5: 432-437.

Cunningham EP and Meghen CM (2001). Biological identification systems: genetic markers. Rev. Sci. Tech. 20: 491-499. 
Dalvit C, De Marchi M, Dal Sotto R and Gervaso M (2008a). Breed assignment test in four Italian beef cattle breeds. Meat Sci. 80: 389-395.

Dalvit C, De MM, Dal ZR, Zanetti E, et al. (2008b). Genetic characterization of the Burlina cattle breed using microsatellites markers. J. Anim. Breed. Genet. 125: 137-144.

Gutiérrez JP, Royo LJ, Alvarez I and Goyache F (2005). MolKin v2.0: a computer program for genetic analysis of populations using molecular coancestry information. J. Hered. 96: 718-721.

Méndez RD, Meza CO, Berruecos JM, Garces P, et al. (2009). A survey of beef carcass quality and quantity attributes in Mexico. J. Anim. Sci. 87: 3782-3790.

Orru L, Napolitano F, Catillo G and Moioli B (2006). Meat molecular traceability: how to choose the best set of microsatellites? Meat Sci. 72: 312-317.

Rodríguez-Ramírez R, Gonzalez-Cordova AF and Vallejo-Cordoba B (2011). Review: Authentication and traceability of foods from animal origin by polymerase chain reaction-based capillary electrophoresis. Anal. Chim. Acta 685: $120-126$.

Smith GC, Tatum JD, Belk KE and Scanga JA (2005). Traceability from a US perspective. Meat Sci. 71: 174-193.

Vázquez JF, Pérez T, Ureña F, Gudín E, et al. (2004). Practical application of DNA fingerprinting to trace beef. J. Food Prot. 67: 972-979.

Vetharaniam I, Shackell GH and Upsdell M (2009). A statistical approach to identifying the batch of origin of mixed-meat products using DNA profiles. J. Food Prot. 72: 1948-1957.

Weir BS (1996). Genetic Data Analysis II. Methods for Discrete Population Genetic Data. Sinauer Associates. Inc. Publishers, Sunderland. 